\title{
Effect of Preheat Temperatures on Mechanical Properties and Polymerization Contraction Stress of Dental Composites
}

\author{
Pavinee P. Didron ${ }^{1 *}$, Ayman Ellakwa ${ }^{2,3}$, Michael V. Swain ${ }^{4}$ \\ ${ }^{1}$ Department of General Dentistry, Faculty of Dentistry, Srinakharinwirot University, Bangkok, Thailand; ${ }^{2}$ Department of Tooth Con- \\ servation, Faculty of Dentistry, University of Sydney, Sydney, Australia; ${ }^{3}$ Faculty of Dentistry, Tanta University, Tanta, Egypt; \\ ${ }^{4}$ Biomaterials Research Unit, Faculty of Dentistry, University of Sydney, Sydney, Australia. \\ Email: "pavineep@hotmail.com, pavinee.didron@gmail.com
}

Received March 31 $1^{\text {st }}, 2013$; revised May 2 ${ }^{\text {nd }}, 2013$; accepted May $16^{\text {th }}, 2013$

Copyright (C) 2013 Pavinee P. Didron et al. This is an open access article distributed under the Creative Commons Attribution License, which permits unrestricted use, distribution, and reproduction in any medium, provided the original work is properly cited.

\begin{abstract}
Objectives: The purpose of this study was to investigate the effect of preheat temperatures on polymerization contraction stress and mechanical properties of three resin composites. Methods: Three resin composites (Filtek Supreme XT, GC Kalore, and Gradia Direct X) at room temperature, $37^{\circ} \mathrm{C}$, and $60^{\circ} \mathrm{C}$ were investigated. Stress development and maximum contraction stress of the composites were evaluated. Directly after preheating, samples were light-cured for 40 seconds and the force recorded for 15 minutes. Subsequent calculations were done to account for the system's compliance and to obtain the shrinkage stress of the composites. In addition, composite discs ( $5 \mathrm{~mm} \varnothing$ and $1 \mathrm{~mm}$ thick) were light-cured for 40 seconds at the preheat temperature. Hardness, elastic modulus, and creep of composites were investigated using a nano-indentation system (UMIS 2000). The results were analyzed using Two-way Analysis of Variance (2-way ANOVA) and Tukey's Post-Hoc test $(\alpha=0.05)$. Results: The results indicated that preheating composites to $37^{\circ} \mathrm{C}$ and $60^{\circ} \mathrm{C}$ increased the polymerization contraction forces, but did not significantly affect hardness, elastic modulus, and creep behaviour of the materials. Analysis of the contraction force upon allowing for thermal contraction indicated only a minor influence of preheat temperature. Significance: Preheating composites, upon allowing for system thermal contraction, showed a slight increase of the polymerization contraction stress but did not significantly affect the composites' mechanical properties.
\end{abstract}

Keywords: Preheating; Dental Composites; Polymerization Shrinkage; Contraction Stress; Nanoindentation; Hardness

\section{Introduction}

Advances in modern technology have resulted in the development of improved dental resin composites [1]. As a result, modern resin composites have become widely used for various purposes in restorative dentistry despite several drawbacks including substantial polymerization shrinkage, inferior wear resistance relative to amalgam, incomplete monomer conversion and undesirable watersorption [2]. The polymerization contraction of bonded resin composites results in tensile stresses developing across the restoration-tooth interface, pulling the material away from the cavity walls [3-5]. This is one of the main causes for marginal failure and subsequent micro-leakage observed with resin composite restorations [6,7]. Contraction forces on cusps can result in cuspal deformation,

${ }^{*}$ Corresponding author. enamel cracks and crazes [8], and ultimately decrease fracture resistance of the cusp [9].

The factors that can affect the polymerization shrinkage are inorganic filler content, the molecular weight and type of monomer system, and the degree of conversion of the monomer system [10-13], whereas the magnitude of contraction stress for a specific resin system is dependent on the cavity configuration (C-factor), which is the ratio of the bonded to unbonded surface area of the restoration [14], the volume of the restoration [15], the nature of the matrix material [16], the filler load [12,17], the viscous-elastic properties $[5,12]$ as well as the polymerization rate $[18,19]$. The ability of the polymer to rearrange and delay or relieve stress build-up (known as flow capacity) has also been shown to influence the magnitude of the final contraction stress [6]. The high viscosity and stickiness of some modern highly filled resin composites, 
can cause difficulties during the composite placement and material adaptation. A commercial device for preheating such composite has been introduced (Calset, AdDent Inc., CT, USA) in order to improve both their flow-ability and adaptation. Most highly filled composites have a lower viscosity when they are preheated [20]. Composites cured at elevated temperatures also have been observed to have an increased polymerization rate and a higher degree of conversion [21-23]. Daronch et al. reported that maximum conversion rate also increased with temperature, the maximum conversion rate at the top surface increased from $11.8 \%$ /sec at room temperature to $23.6 \% / \mathrm{sec}$ at $60^{\circ} \mathrm{C}$ [23]. Prasanna et al, also found an increase in the degree of conversion of preheated composites [24]. It however has been reported that the increased degree of conversion associated with preheating may result in increased polymerization shrinkage [25].

The main objective of this study is to investigate the effect of preheat temperatures on contraction stress produced in resin composites during polymerization. The second objective is to evaluate the effect preheat temperature has on the mechanical properties of resin composites (nano-hardness, elastic modulus, and creep). It was hypothesized that increasing the preheat temperature would increase the polymerization conversion of composites and thereby increase the contraction stresses and improve their mechanical properties.

\section{Materials and Methods}

\subsection{Materials}

The materials used in this study are indicated in Table $\mathbf{1 .}$

\subsection{Nanoindentation}

Three disc specimens were made for each material by placing composite in a Teflon split mould between two Mylar strips and pressed manually with two flat glass slides resulting in a thin disc $(5 \mathrm{~mm} \varnothing \times 1 \mathrm{~mm}$ thick). The disc was light-cured for 40 seconds on both sides using LED-light curing machine (MiniLED, Satelec, France). Hardness, elastic modulus, and creep of composites were investigated using a nano-based indentation system (Ultra Micro-Indentation System, UMIS-2000,
CSIRO, Australia). Samples were indented with a calibrated (with fused silica standard) Berkovich indenter (Synton, Switzerland). The force applied ranged from 10 to $100 \mathrm{mN}$. The software based on the Oliver and Pharr method [26] calculated elastic modulus and hardness as a function of penetration depth, $h_{\mathrm{p}}$, for each indentation. At least 15 indents at 3 different areas were done on each sample to acquire the average values. Creep of each material was calculated by dividing the displacement at the maximum load of each indentation by holding time (20 sec).

\subsection{Polymerization Contraction Force Measurement and Polymerization Stress Calculation}

Polymerization contraction stress was measured by a purpose built device which consists of 2 parts; the first part is a load cell, in which a brass piston was attached. A brass piston $(10 \mathrm{~mm} \varnothing \times 30 \mathrm{~mm}$ length) was used as the bonding substrate for the composite. The piston had one surface abraded with \#180-grit sandpaper, coated with silane coupling agent prior to the application of a thin layer of unfilled resin (Adper ${ }^{\mathrm{TM}}$ Single Bond 2), and light-cured for $20 \mathrm{sec}$ (MiniLED, Satelec, France). A ring-shape teflon $(\mathrm{C}$ mold was inserted at the end of the brass piston, creating a cylindrical cavity $(10 \mathrm{~mm} \varnothing \times 1$ mm thick) for the resin composite. Uncured resin composite was preheated, inserted in the mold, and the mold was removed. The brass piston with the composite was heated up to specific test temperature on a thermal-controlled plate, a thermocouple (Fluke 52, Fluke Corporation, USA) was placed inside a hole in the brass piston at all times to measure the composite temperature. The second part is a brass cylinder, holding a clear perspex $\operatorname{disc}(22 \mathrm{~mm} \varnothing \times 1 \mathrm{~mm}$ thick). The brass cylinder has a slot which allowed for the placement of the light guide of a curing unit in contact with the perspex disc. The top surface of perspex disc was abraded with \#180-grit sandpaper, cleaned, coated with a thin layer of unfilled resin (Adper ${ }^{\mathrm{TM}}$ Single Bond 2), and light-cured for $20 \mathrm{sec}$. When the desired temperature was reached, the brass piston was fixed to the load cell. The brass piston was driven down until the composite just touched the perspex surface, the crosshead of the testing machine was stopped

Table 1. materials tested in the present study, their reported volumetric shrinkage, respective batch number and manufacturer.

\begin{tabular}{cccc}
\hline Material & Volumetric shrinkage (\%) & Manufacturer & Batch number \\
\hline Filtek $^{\text {TM }}$ Supreme XT & $1.72 \%$ & 3M ESPE, Dental Products, St.Paul MN & N151598 \\
GC KALORE & $2.40 \%$ & GC Corporation, Tokyo, Japan & 910071 \\
Gradia & $2.00 \%$ & GC Corporation, Tokyo, Japan & 1201271 \\
\hline
\end{tabular}


when a load of $0.1 \mathrm{~N}$ was observed. The composite was photo-activated through the clear perspex disc as shown in Figure 1. As the composite polymerized, contraction force was followed for 15 mins and the maximum force recorded. The force values were converted to nominal stress by dividing them by the cross-sectional surface area of the specimen $\left(78.5 \mathrm{~mm}^{2}\right)$. Maximum contraction stress and maximum rate of force development, calculated from the first derivative of the contraction force vs. time curves, were subjected to statistical analysis.

\subsection{Polymerization Shrinkage Measurement}

Three samples for each group were prepared in a similar way as for the contraction stress measurement. The brass piston with the composite was heated up to a specific test temperature on a thermal-controlled plate, a thermocouple (Fluke 52, Fluke Corporation, USA) was placed inside a hole in the brass piston at all times to measure the composite temperature. A comparator (MINICOM model E-MD-M30 J, Tokyo Seimitsu, Japan) with a resolution of $0.5 \mu \mathrm{m}$ was used to detect the linear shrinkage produced during polymerization. The shrinkage was followed for 15 mins.

\subsection{Compliance Compensation}

The load cell and testing machine compliance $(\mu \mathrm{m} / \mathrm{N})$ was calibrated by loading in tension with standard weights

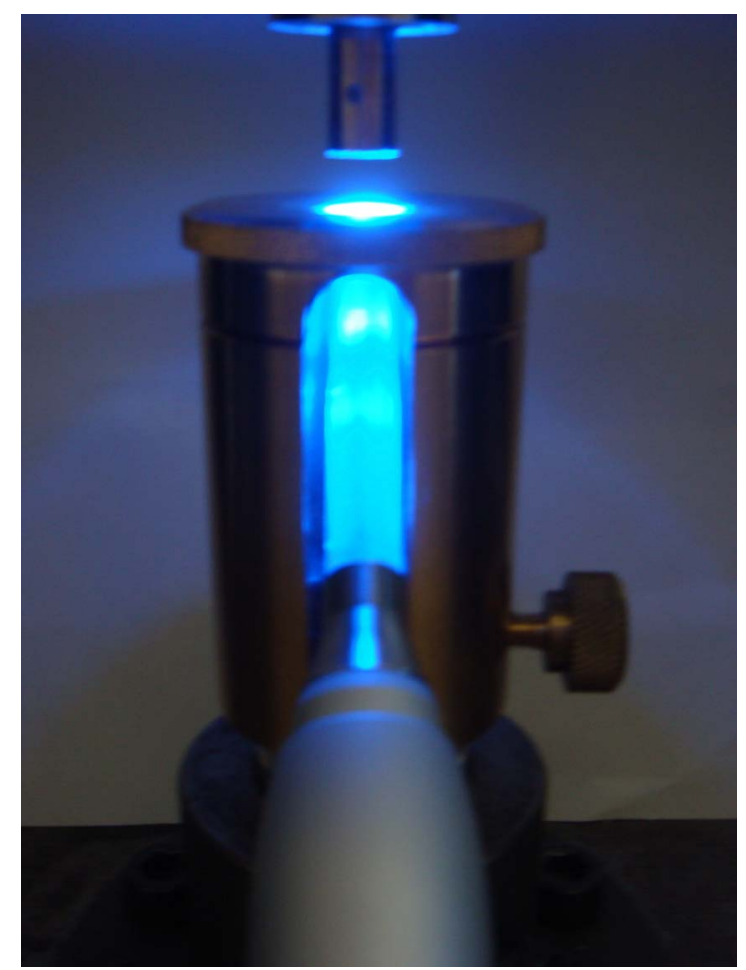

Figure 1. The test setup for the polymerization stress measurements. up to $500 \mathrm{~N}$. The recorded values were compared with the actual loads. The same comparator (MINICOM model E-MD-M30 J, Tokyo Seimitsu, Japan) was also used to detect deflection of the load cell and the supporting system.

\subsection{Statistical Analysis}

The results were analyzed using Two-way Analysis of Variance (2-way ANOVA) and Tukey's Post-Hoc test ( $\alpha$ $=0.05)\left(\mathrm{IBM}^{\circledR} \mathrm{SPSS}^{\circledR}\right.$ statistics 20, USA).

\section{Results}

\subsection{Mechanical Properties}

Results for hardness, elastic modulus and creep rate are shown in Figure 2. For all mechanical properties tested, statistically significant differences were detected between different materials $(\mathrm{P}<0.05)$, but no significant differences were found between materials preheat temperatures.

\subsection{Polymerization Shrinkage}

Polymerization volumetric shrinkage results are shown in Figure 3. For all materials, the volumetric shrinkage increased significantly $(\mathrm{P}<0.01)$ with the increase in temperature.

\subsection{Polymerization Force Development}

Typical observations of the force development as a function of time for the 3 materials at room temperature, $37^{\circ} \mathrm{C}$, and $60^{\circ} \mathrm{C}$ are shown in Figure 4. All materials exhibited a significant force increase between 5 and $40 \mathrm{sec}$, which then continued to increase at a slower rate. The extent of force development beyond $1 \mathrm{~min}$ was in all instances greater at elevated temperatures. This pattern was consistent for all temperatures.

Mean values and standard deviations of the contraction forces recorded at 1 and $15 \mathrm{~min}$ are shown in Table 2. The calculated maximum contraction stresses at $15 \mathrm{~min}$ ute are listed in Table 3 and maximum rates of force development are listed in Table 4.

Statistically significant differences were detected between different materials and temperatures $(\mathrm{P}<0.05)$ for both contraction force and rate of force development. GC Kalore exhibited the lowest stress values, followed by Gradia Direct X and Filtek Supreme XT. For all composites tested, increasing the preheat temperature significantly increased the contraction force, contraction stress, and rate of force development $(\mathrm{P}<0.05)$.

\subsection{Compliance Compensation}

Results from the Calibration of the load cell show that the comparator moved $9 \mu \mathrm{m}$ for every $100 \mathrm{~N}$ load applied. 

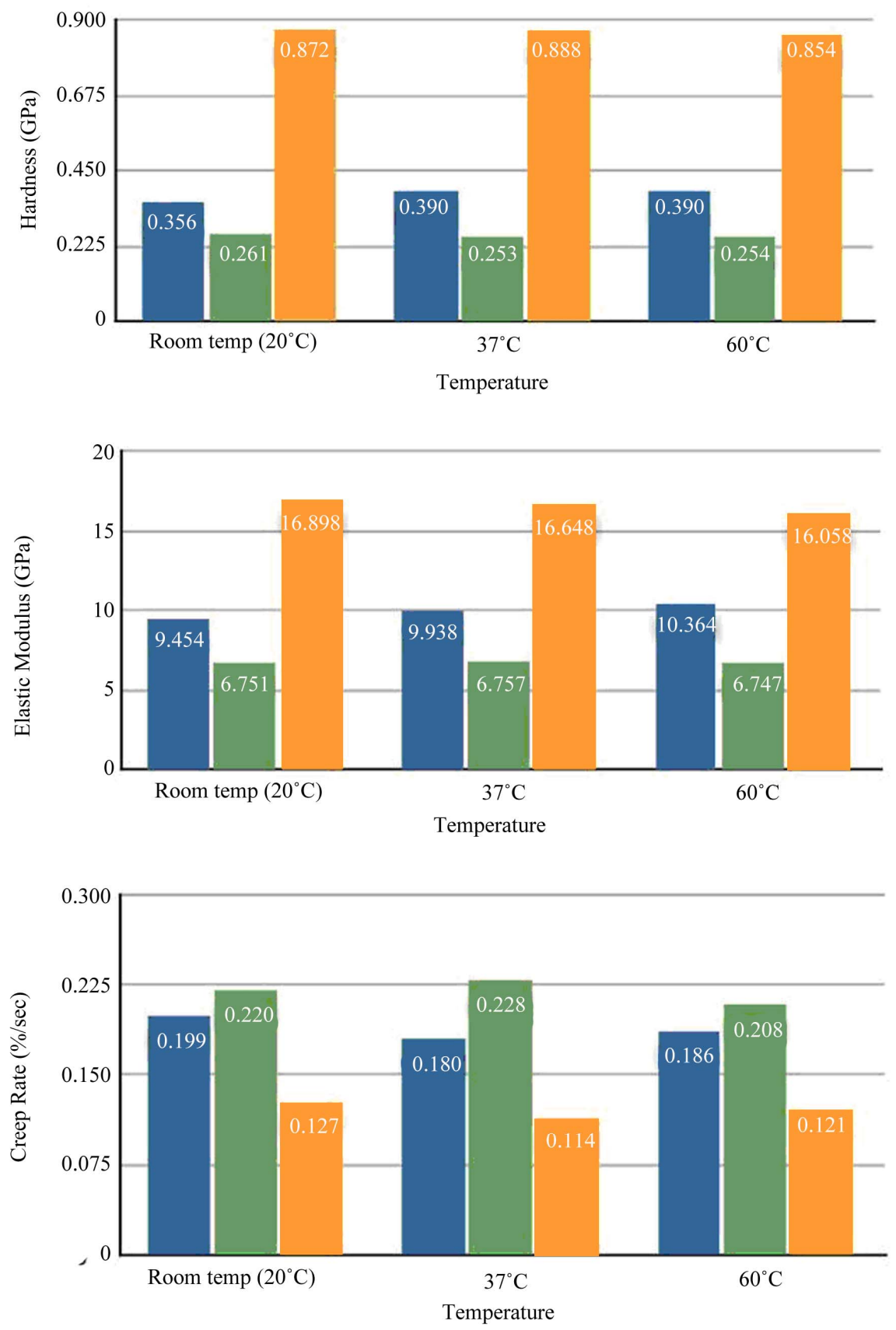

GC Kalore Gradia Direct X IIII Filtek Supreme XT

Figure 2. Mechanical properties of composites at 3 temperatures.

Therefore the results need to be adjusted proportionally to the contraction force values. To calculate the contraction stress that would have developed if the load cell and support system had been infinitely stiff and assuming that no further relaxation or creep takes place during polymerization, the calculation of the deformation due to compliance of the system at 15 minute was done. Knowing the maximum force developed and the compliance enables the effective deflection of the system to be estimated. Also knowing the dimensions and elastic properties of the support structure (Brass rod and bonding resin), the effective additional force generated had the load cell been infinitely rigid were calculated. The resultant corrected contraction stresses are listed in Table 5. Interestingly, the stress results obtained from calculation are much higher than the original results obtained directly 


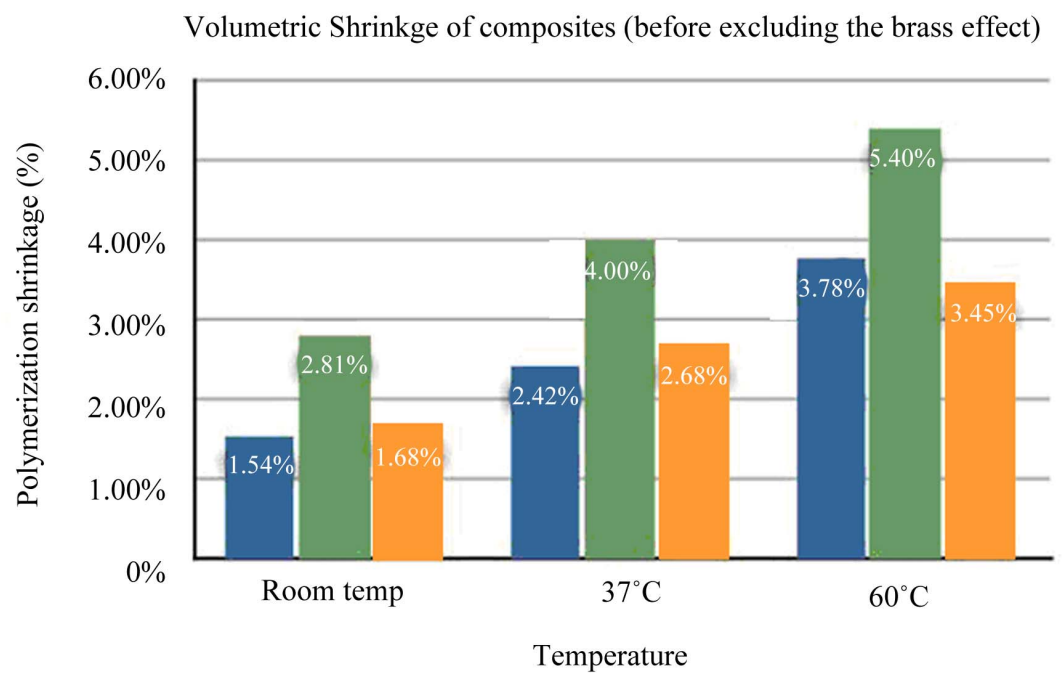

Kalore

Gradia Direct X

Filtek Supreme XT

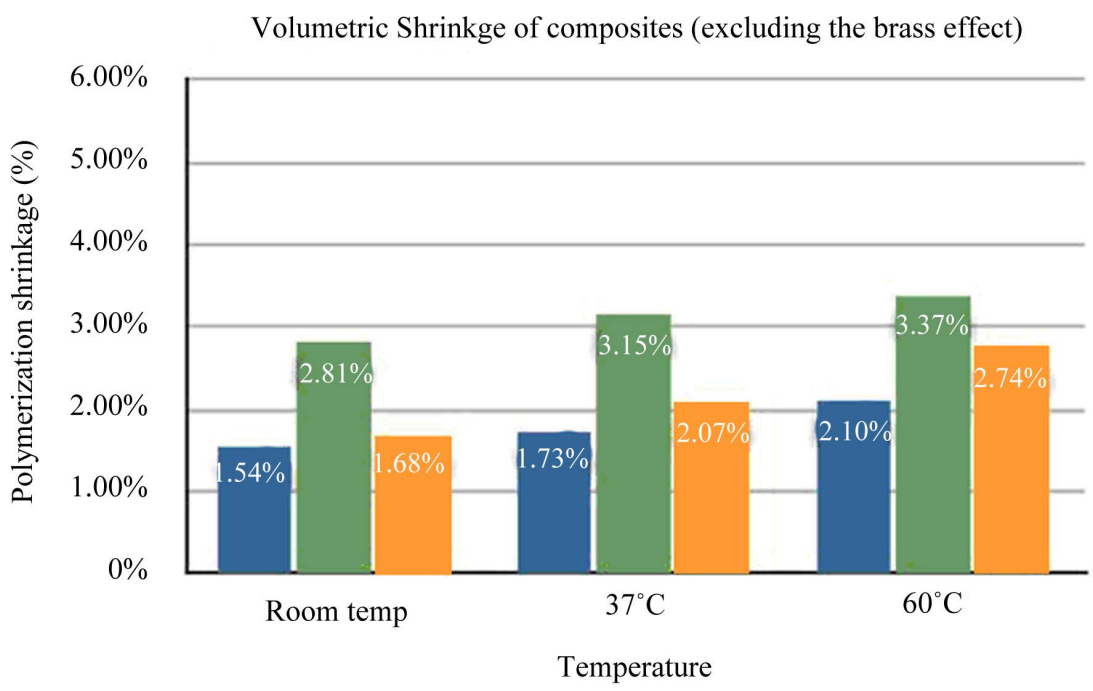

Kalore

Gradia Direct X

Filtek Supreme XT

Figure 3. Polymerization volumetric shrinkage of composites.

from the contraction force measurements (Tables 3 and 4). Similar to the observed results, calculated stresses (Table 5) show statistically significant difference between materials and temperatures. For all composites, increasing the composite temperature significantly increased the contraction stress $(\mathrm{P}<0.05)$.

\section{Discussion}

The aim of this study was to evaluate the effect of preheat temperatures on the mechanical properties of composites, and to investigate its impact on polymerization contraction and subsequent contraction stress produced in resin composites. For the two composites tested, Filtek Supreme and Gradia Direct X, preheating to $60^{\circ} \mathrm{C}$ leads to a slight decrease in all tested mechanical properties. As shown in Figure 2, at $60^{\circ} \mathrm{C}$ Filtek Supreme presents a
$2.1 \%$ decrease in nanohardness, $5 \%$ decrease in elastic modulus, and $4.7 \%$ decrease in creep rate, whereas Gradia Direct $X$ shows a $2.7 \%$ decrease in nanohardness, $0.06 \%$ decrease in elastic modulus, and $5.5 \%$ decrease in creep rate. On the other hand, preheating GC Kalore to $60^{\circ} \mathrm{C}$ resulted in a $9.6 \%$ increase in nanohardness and elastic modulus, and produced a $6.5 \%$ decrease in creep rate. Overall, the results indicated that there was no statistically significant difference in mechanical properties (Hardness, Elastic modulus, and creep) of the cured resin composite after preheating to $37^{\circ} \mathrm{C}$ and $60^{\circ} \mathrm{C}$. This would imply that the degree of conversion of the tested composites is not noticeably affected by the preheat temperature although one would have initially thought that hardness, elastic modulus, and creep rate would have been particularly dependent on the degree of conversion. It appears that the depth of the nano-indentation penetra 


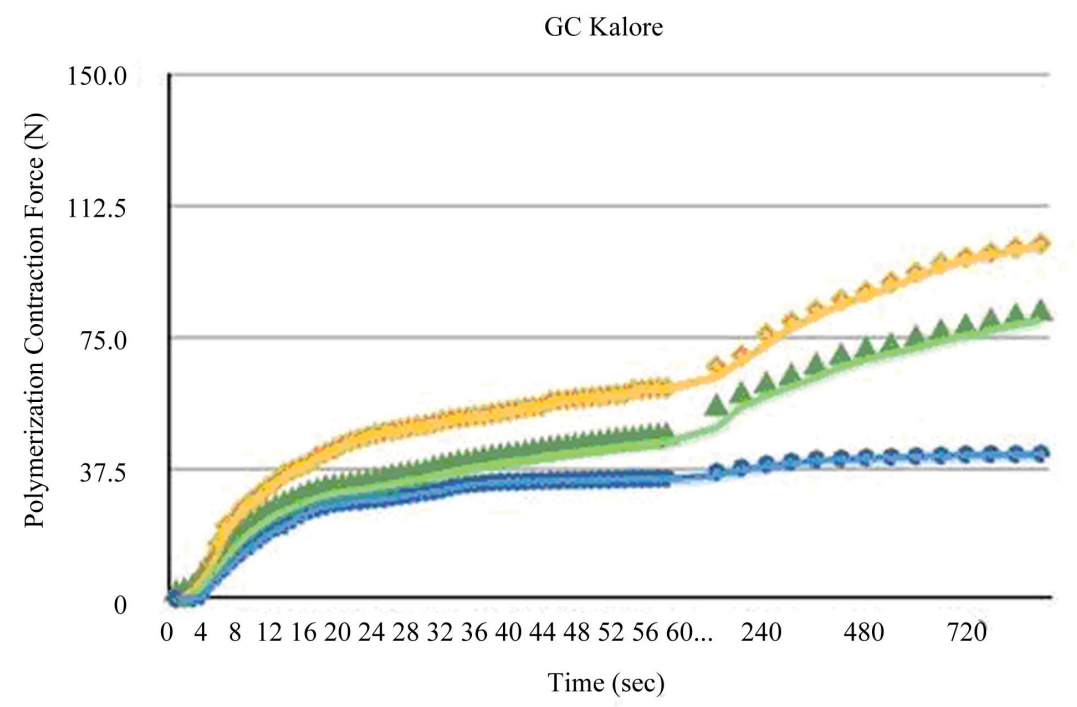

$$
\begin{aligned}
& \star \text { Room Temp } \\
& \triangle 37 \mathrm{C} \\
& \diamond 60 \mathrm{C}
\end{aligned}
$$

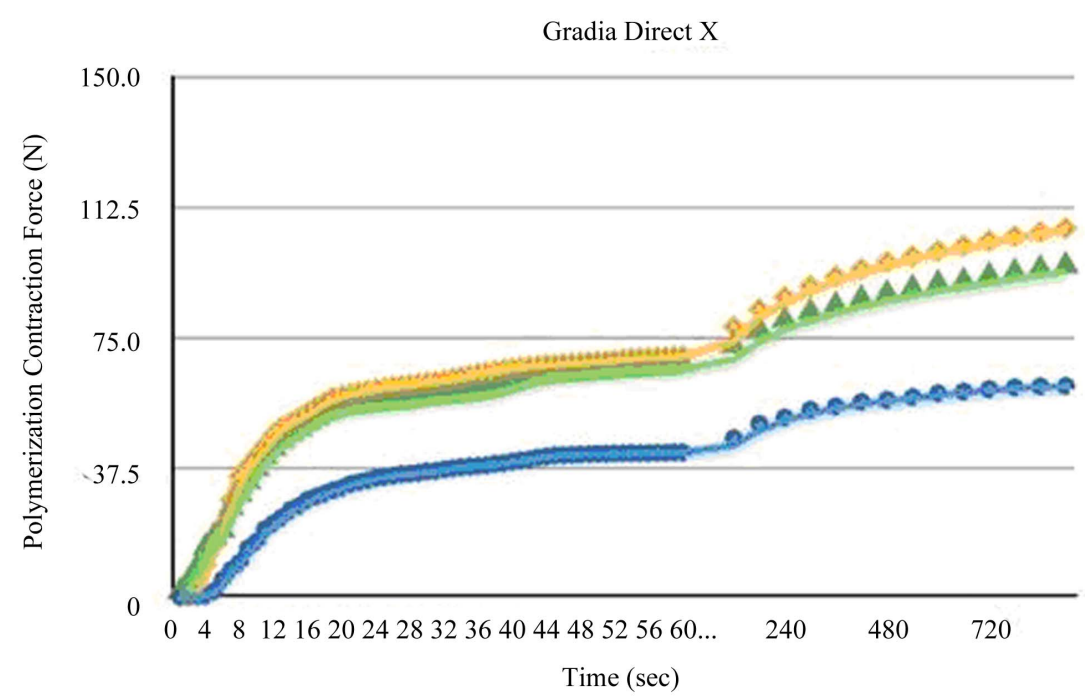

- Room Temp

$\Perp 37 \mathrm{C}$

$\% 60 \mathrm{C}$

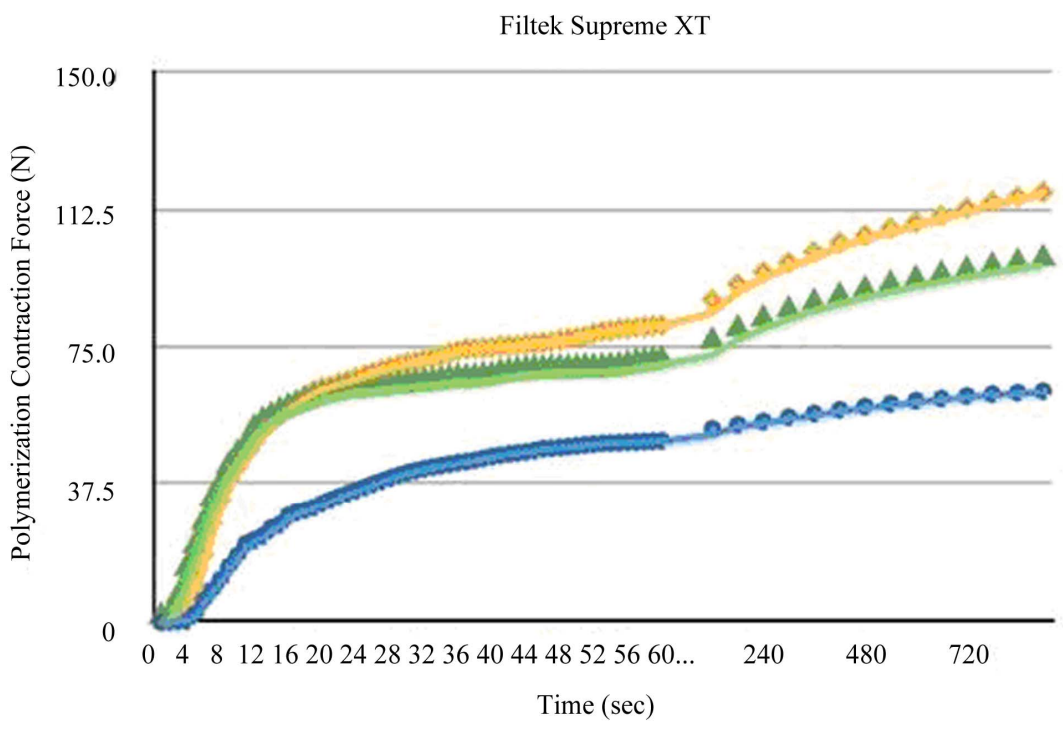

Room Temp

ㅅ․ $37 \mathrm{C}$

$\Leftrightarrow 60 \mathrm{C}$

Figure 4. Polymerization contraction force development curves. 
Table 2. Means and standard deviations of the polymerization contraction force (N) at 1 and 15 minute.

\begin{tabular}{ccccccc}
\hline Temperature & \multicolumn{2}{c}{ Room temp } & \multicolumn{2}{c}{$37^{\circ} \mathrm{C}$} & \multicolumn{2}{c}{$60^{\circ} \mathrm{C}$} \\
\hline Material/ Time & 1 minute & 15 minute & 1 minute & 15 minute & 1 minute & 15 minute \\
\hline GC Kalore & $35.6(5.4)$ & $40.9(2.6)$ & $41.5(1.5)$ & $77.7(10.3)$ & $59.4(0.7)$ & $93.9(6.9)$ \\
Gradia Direct X & $43.5(3.1)$ & $59.3(3.4)$ & $65.1(2.1)$ & $91.1(4.7)$ & $68.9(0.9)$ & $113.3(6.9)$ \\
Filtek Supreme XT & $49.3(0.2)$ & $61.4(1.7)$ & $71.4(0.7)$ & $95.9(4.7)$ & $83.0(2.0)$ & $118.4(1.1)$ \\
\hline
\end{tabular}

Table 3. Means and standard deviations of the maximum polymerization contraction stress (MPa) at 15 minute.

\begin{tabular}{cccc}
\hline Material/Temperature & Room temp & $37^{\circ} \mathrm{C}$ & $60^{\circ} \mathrm{C}$ \\
\hline GC Kalore & $0.55(0.03)$ & $1.08(0.13)$ & $1.28(0.09)$ \\
Gradia Direct X & $0.76(0.04)$ & $1.16(0.06)$ & $1.44(0.09)$ \\
Filtek Supreme XT & $0.78(0.02)$ & $1.22(0.06)$ & $1.51(0.01)$ \\
\hline
\end{tabular}

Table 4. Maximum rate of force development (N/sec) and Time to achieve the maximum rate (sec).

\begin{tabular}{ccccccc}
\hline \multirow{2}{*}{ Material/ Temperature } & \multicolumn{2}{c}{ Room temp } & \multicolumn{2}{c}{$37^{\circ} \mathrm{C}$} & \multicolumn{2}{c}{$60^{\circ} \mathrm{C}$} \\
\cline { 2 - 7 } & Rmax (N/sec) & Time to Rmax & Rmax (N/sec) & Time to Rmax & Rmax (N/sec) & Time to Rmax \\
\hline GC Kalore & $2.7(0.4)$ & $5.6(0.6)$ & $3.1(0.3)$ & $7.0(0.0)$ & $4.1(0.5)$ & $5.6(0.6)$ \\
Gradia Direct X & $4.4(0.6)$ & $8.0(0.0)$ & $6.9(0.8)$ & $7.0(0.0)$ & $8.6(0.9)$ & $4.6(1.7)$ \\
Filtek Supreme XT & $3.8(0.5)$ & $6.6(1.2)$ & $7.7(0.6)$ & $4.3(0.6)$ & $8.8(1.2)$ & $5.6(0.6)$ \\
\hline
\end{tabular}

Table 5. Adjusted maximum contraction stress values (MPa) from a calculation.

\begin{tabular}{ccccc}
\hline Material/Temperature & Room temp & $37^{\circ} \mathrm{C}$ & $60^{\circ} \mathrm{C}$ & 16.2 \\
\hline GC Kalore & 8.35 & 11.21 & 17.24 & 21.43 \\
Gradia Direct X & 13.93 & 21.79 & 26.87 \\
Filtek Supreme XT & 13.93 & 21 \\
\hline
\end{tabular}

tion is not a genuine indicator of the bulk properties of these cured composites. Recently, Nada and El-Mowafy found a significant increase in surface microhardness of two of the three tested composites, and a significant increase in diametral tensile strength and compressive strength in one of the three materials, after preheating [27]. Muñoz et al. also reported an increase in surface hardness with preheating to $37^{\circ} \mathrm{C}$ and $60^{\circ} \mathrm{C}$; however, different composites were tested [28]. They concluded that composites behave differently with heat treatment resulting in different mechanical properties. This may explain the results in this study since each of the three composites tested behaved differently after heat treatment.

The polymerization shrinkage results, before and after exclusion of the brass thermal contraction effect (Tables 6 and 7), showed that the contribution of the brass is a substantial fraction of the total contraction especially when preheated to $60^{\circ} \mathrm{C}$. For all materials, the measured polymerization shrinkage increased in value with tem- perature elevation. This increase was highly significant $(\mathrm{P}<0.01)$ before excluding the brass effect. However, after exclusion of the brass effect, the increase was only just significant $(\mathrm{P}<0.05)$. This again emphasises the substantial contribution of the brass contraction to the raw shrinkage values in the current study.

Similar to the shrinkage results, preheating composites significantly increased the measured polymerization contraction force. Preheating composites from $20^{\circ} \mathrm{C}$ to $37^{\circ} \mathrm{C}$, without taking into account the thermal contraction of the brass, resulted in a contraction stress increase of $96.4 \%$ for GC Kalore, $52.6 \%$ for Gradia Direct X, and 56.4\% for Filtek Supreme, whereas preheating composites from $20^{\circ} \mathrm{C}$ to $60^{\circ} \mathrm{C}$ resulted in a contraction stress increase of $132.7 \%$ for GC Kalore, $89.5 \%$ for Gradia Direct X, and 93.6\% for Filtek Supreme. As shown in Table 5, contraction stress results after compensated for the test system compliance showed much higher values than the experimental results, however exclusion of the thermal contraction of the brass (by calculation) resulted in 
Table 6. Shrinkage $(\mu \mathrm{m})$ of the test systems (including the brass piston) at 1 and 15 minute.

\begin{tabular}{|c|c|c|c|c|c|c|}
\hline \multirow{2}{*}{ Material/Temperature } & \multicolumn{2}{|c|}{ Room temp } & \multicolumn{2}{|c|}{$37^{\circ} \mathrm{C}$} & \multicolumn{2}{|c|}{$60^{\circ} \mathrm{C}$} \\
\hline & $1 \mathrm{~min}$ & $15 \mathrm{~min}$ & $1 \mathrm{~min}$ & $15 \mathrm{~min}$ & $1 \mathrm{~min}$ & $15 \mathrm{~min}$ \\
\hline GC Kalore + Brass & 15 & 18.67 & 27.5 & 28.67 & 42.5 & 46.5 \\
\hline Gradia Direct $X+$ Brass & 18 & 25.83 & 30 & 37.33 & 45 & 53 \\
\hline Filtek Supreme XT + Brass & 17.5 & 22 & 30 & 34.83 & 42.5 & 48.17 \\
\hline Brass & 0 & 0 & 5.5 & 8.5 & 15.5 & 20.33 \\
\hline
\end{tabular}

Table 7. Shrinkage $(\mu \mathrm{m})$ of composites after exclusion of the brass contraction.

\begin{tabular}{|c|c|c|c|c|c|c|}
\hline \multirow{2}{*}{ Material/ Temperature } & \multicolumn{2}{|c|}{ Room temp } & \multicolumn{2}{|c|}{$37^{\circ} \mathrm{C}$} & \multicolumn{2}{|c|}{$60^{\circ} \mathrm{C}$} \\
\hline & $1 \mathrm{~min}$ & $15 \min$ & $1 \mathrm{~min}$ & $15 \mathrm{~min}$ & $1 \mathrm{~min}$ & $15 \mathrm{~min}$ \\
\hline GC Kalore & 15 & 18.67 & 22 & 20.17 & 27 & 26.17 \\
\hline Gradia Direct X & 18 & 25.83 & 24.5 & 28.83 & 29.5 & 32.67 \\
\hline Filtek Supreme XT & 17.5 & 22 & 24.5 & 26.33 & 27 & 27.84 \\
\hline
\end{tabular}

minimal stress increase for all groups.

The results from this study showed that a major contribution to the higher forces and stresses at elevated temperatures is the thermal contraction effect of the heated test system (brass piston + bonding resin + composite) rather than a consequence of greater conversion of composite. This is because the mechanical properties of the composites would have been improved if they have greater conversion. The brass piston is $31 \mathrm{~mm}$ in length and has a thermal expansion coefficient of $18.5 \times$ $10^{-6} \rho \mathrm{C}$, the bonding resin thickness is $0.1 \mathrm{~mm}$ and has a thermal expansion coefficient of $60 \times 10^{-6} \rho \mathrm{C}$, whereas the composites is $1 \mathrm{~mm}$ thick and typically have a thermal expansion coefficient of $40 \times 10^{-6} \rho \mathrm{C}$. Thus these components all contribute to a substantial amount to the contraction force.

Polymerization shrinkage and shrinkage strain both have been shown to increase proportionally with the composite temperature, from $2 \%$ at room temperature to $5 \%$ at $60^{\circ} \mathrm{C}$, for a range of composites [22,23,29-31]. Thus the increased polymerization forces at elevated temperatures were far greater than previously measured increases in the degree of conversion. One might also have thought that the increased polymerization conversion would have increased the mechanical properties and decreased the creep rate but this was not observed in two of the three composites tested. As mentioned earlier, only GC Kalore showed an increase in nanohardness and elastic modulus, and a decrease in creep rate, but these were not significant.
Contraction stress development of dental composites depends on both material compositional factors and composite polymerization factors $[32,33]$. The resin matrix of Filtek Supreme XT contains a mixture of BisGMA and TEGDMA, added to Urethane dimethacrylate (UDMA) and Bis-EMA resin, whereas the resin matrix of GC Kalore is based on DX-511 monomer, and the resin matrix of Gradia Direct X consists of a mixture of UDMA and dimethacrylate co-monomers (information from manufacturer and products' data sheet). Bis-EMA, contained in Filtek Supreme XT (which also has a higher filler content), is a less flexible and more viscous monomer [34], both of which may account for Filtek Supreme XT generating the high stress values observed. Dx-511 monomer is claimed to have higher molecular weight (MW 895) and therefore less polymerization shrinkage, in comparison to Bis-GMA (MW 512.6). The results show that GC Kalore and Gradia Direct X produce less shrinkage stress than Filtek Supreme XT. If we compare the stress increase values for each system between 1 and 15 minutes (Table 2), then the $60^{\circ} \mathrm{C}$ preheated system shows much greater increase than the $37^{\circ} \mathrm{C}$ and room temperature results. The linear shrinkage results however showed a comparable increase in shrinkage between 1 and 15 minutes, upon comparison of the values at room temperature, $37^{\circ} \mathrm{C}$ and $60^{\circ} \mathrm{C}$ (Table 6). Interestingly, if we exclude the brass contraction from the values at $37^{\circ} \mathrm{C}$ and $60^{\circ} \mathrm{C}$ (Table 7), then the increase in shrinkage from 1 to 15 minute is less when preheated composite to higher temperature. 
The contraction force versus time curves of composites cured at room temperature showed an S-shape profile similar to that previously reported $[32,35,36]$. A slow increase at the start indicating a slight expansion of the composite which can be due to the temperature increases by the starting of the curing unit as described by Chen et al. [35,36]. A different profile was found for the other groups cured at elevated temperatures, their initiation state of the polymerization seems to be shorter and resulted in higher rate of force development than those cured at room temperature.

Maximum rate of force development increased with temperature for all composites. The time to reach the maximum rate of force development ranged from 4.3 to 8 seconds and did not show a clear trend. These outcome were in agreement with previous studies, which reported an increase in maximum conversion rate of composites with increased temperature [21,23,37]. Daronch et al. investigated polymerization kinetics of preheated composite, they found that composite reacts quickly once light exposure is initiated and time to achieve maximum conversion rate $\left(\mathrm{t}_{\max }\right)$ occurred before $5 \mathrm{sec}$ at $2-\mathrm{mm}$ depth, and under $3 \mathrm{sec}$ at the top surface, however, they found no significant change with temperatures [23]. Other studies also found that $t_{\max }$ can increase or remain almost constant [38], or even decrease with reduction in temperature [39]. Therefore $t_{\max }$ seems to be dependent on the system nature and on the experimental conditions used [23]. Plots of Rate of force development versus Time show similar pattern for all materials. The highest rate of force development were found during the first 4 10 seconds then gradually decreased. A higher rate was found with increase in preheat temperature.

One of the major problems related to stress measurement systems is their compliance. In experimental setups with near zero compliance (when the load-cell and supporting system is infinitely stiff) such as the setups with a feedback control system, the deformation that occurs outside the extensometer limits can be excluded [40]. Without a feedback control system, composite contraction is able to elastically deform the load recording system (load cell + testing machine + testing jig) which therefore dissipates part of the contraction force through deformation of the testing device. This type of setup results in much lower recorded force values than those obtained with near zero compliance systems $[35,41,42]$. The recorded force values in this study were therefore underestimated and need to be compensated for the system compliance. After adding additional force to the results, as outlined in the appendix to accommodate for the system compliance compensation, the force and associated tensile stress results are much higher than the recorded values although they demonstrate a similar pattern. The calculated stresses, assuming no creep relaxa- tion stress during curing, the maximum values at $10 \mathrm{~min}-$ utes range from $6.2-11.5 \mathrm{MPa}$, and at 15 minutes range from $8.4-13.9 \mathrm{MPa}$ at room temperature, which are comparable to the previous reported maximum stress findings with rigid or feedback controlled-compliance apparatus at room temperature which range from 4.4 11.6 $\mathrm{MPa}[3,40,43]$. In addition, the amounts of stress increase when composites were preheated from room temperature to $37^{\circ} \mathrm{C}$ and from $37^{\circ} \mathrm{C}$ to $60^{\circ} \mathrm{C}$ are comparable for all materials. An explanation is that the calculated force assumes that no relaxation or creep occurs during the build up of the higher forces which certainly would not be the case. Viscoelastic and flowability of composite play an important role in lowering the contraction stress [44]. The stresses due to volume shrinkage are partly relieved by the viscous flow or creep process of the material. This may be the reason why simple elastic stress calculations based on total volume shrinkage and final modulus of the material will give much higher stress values than those actually observed [44].

The interfacial contraction stress occurs during polymerization because the composite is constrained by the bonded surfaces. The configuration factor of the cavity (C-factor), the ratio of the bonded to un-bonded surfaces of the restoration, is one of the main factors in the development of the contraction stress in resin composite restorations $[35,41,42]$. In the present experimental setup, the resin composites were placed in a cylindrical cavity (10 $\mathrm{mm} \varnothing \times 1 \mathrm{~mm}$ thickness), constrained by two composite bonded surfaces, which allowed some degree of composite flow at the unbonded edge surfaces. The C-factor of composite in this setup is 5 (157/31.4) which is considered high [14]. When placing a restoration with the preheated composite, upon placement the tooth will begin to heat up because of the heat transfer from the composite. The tooth will slightly expand while the composite will begin to cool down $[45,46]$. When the curing light is switched on, there will be a slight increase in composite temperature followed by a rapid volumetric shrinkage of composite as polymerization occurs. A limited space for composite relaxation and the rigidity of enamel surrounding the cavity will limit the deflection of the tooth, resulting in the development of higher stresses. According to Hooke's law, stress is determined by the stiffness of the material when subjected to a given strain. Therefore, the higher the elastic modulus and the polymerization shrinkage of the composite, the higher the contraction stress will be.

Polymerization stress development also depends on polymerization kinetics [33]. In general, the composites exhibited a significant stress increase during the first 40 seconds when it rapidly polymerized and acquired its rigidity [32]. The rate of contraction force development is higher during the light polymerization and continues 
after exclusion of the light source. In the present study, the maximum rates of force development increased significantly with temperatures $(\mathrm{p}<0.05)$. The plots between rate of force development versus time show a continuation of contraction force after exclusion of the light, which also increased with the temperatures.

\section{Conclusion}

This study demonstrates the strong influence of composite temperature on polymerization contraction behaviour of dental resin composites. Preheating composites to higher temperature significantly increased the rate of polymerization and polymerization contraction stress. The increased stress at elevated temperature seems to be a consequence of the system thermal contraction rather than an increase in materials' conversion, since the composites' mechanical properties were not significantly improved at elevated temperatures.

\section{Acknowledgements}

This research was supported by The Australian Government's Endeavour Executive Award 2012 and The University of Sydney Biomaterials Research Unit. The support and assistance of Mr. Ken Tyler were greatly appreciated. The authors thank Acteon Australia and New Zealand for supplying the equipment, GC Corporation and 3M ESPE for supplying the materials.

\section{REFERENCES}

[1] R. M. Carvalho, J. C. Pereira, M. Yoshiyama and D. H. Pashley, "A Review of Polymerization Contraction: The Influence of Stress Development versus Stress Relief," Operative Dentistry, Vol. 21, 1996, pp. 17-24.

[2] J. L. Ferracane, "Dental Composites: Present Status and Research Directions," Transactions of the Second International Congress on Dental Materials, Academy of Dental Materials, Honolulu, 1993, pp. 43-53.

[3] J. L. Ferracane and J. C. Mitchem, "Relationship between Composite Contraction Stress and Leakage in Class V Cavities," American Journal of Dentistry, Vol. 16, No. 4, 2003, pp. 239-243.

[4] A. H. Suliman, D. B. Boyer and R. S. Lakes, "Polymerization Shrinkage of Composite Resins: Comparison with Tooth Deformation," The Journal of Prosthetic Dentistry, Vol. 71, No. 1, 1994, pp. 7-12. doi:10.1016/0022-3913(94)90247-X

[5] R. R. Braga and J. L. Ferracane, "Alternatives in Polymerization Contraction Stress Management," Critical Reviews in Oral Biology \& Medicine, Vol. 15, No. 3, 2004, pp. 176-184. doi:10.1177/154411130401500306

[6] C. L. Davidson, A. J. De Gee and A. Feilzer, "The Competition between the Composite-Dentin Bond Strength and the Polymerization Contraction Stress," Journal of Dental Research, Vol. 63, No. 2, 1984, pp. 146-148.

\section{doi:10.1177/00220345840630021001}

[7] B. Kahler, A. Kotousov and M. V. Swain, "On Design of Dental Resin-Based Composites: A Micromechanical Approach," Acta Biomaterialia, Vol. 4, No. 1, 2008, pp. 165-172. doi:10.1016/j.actbio.2007.06.011

[8] M. A. Marzouck and J. A. Ross, "Cervical Enamel Crazing Associated with Occluso-Proximal Composite Restorations in Posterior Teeth," American Journal of Dentistry, Vol. 2, No. 6, 1989, pp. 323-327.

[9] K. F. Wiecz, R. B. Joynt, R. Klockowski and E. L. Davis, "Effects of Incremental versus Bulk Fill Technique on Resistance to Cuspal Fracture of Teeth Restored with Posterior Composites," The Journal of Prosthetic Dentistry, Vol. 60, No. 3, 1988, pp. 283-287. doi:10.1016/0022-3913(88)90269-7

[10] A. Peutzfeldt, "Resin Composites in Dentistry: The Monomer Systems," European Journal of Oral Sciences, Vol. 105, No. 2, 1997, pp. 97-116. doi:10.1111/j.1600-0722.1997.tb00188.x

[11] J. S. Rees and P. H. Jacobsen, "The Polymerization Shrinkage of Composite Resins," Dental Materials, Vol. 5, No. 1, 1989, pp. 41-44. doi:10.1016/0109-5641(89)90092-4

[12] R. Labella, P. Lambrechts, B. Van Meerbeek and G. Vanherle, "Polymerization Shrinkage and Elasticity of Flowable Composites and Filled Adhesives," Dental Materials, Vol. 15, 1999, pp. 128-137. doi:10.1016/S0109-5641(99)00022-6

[13] S. Rüttermann, S. Krüger, W. H. Raab and R. Janda, "Polymerization Shrinkage and Hygroscopic Expansion of Contemporary Posterior Resin-Based Filling Materials: A Comparative Study," Journal of Dentistry, Vol. 35, No. 10, 2007, pp. 806-813. doi:10.1016/j.jdent.2007.07.014

[14] A. J. Feilzer, A. J. De Gee and C. L. Davidson, "Setting Stress in Composite Resin in Relation to Configuration of the Restoration," Journal of Dental Research, Vol. 66, No. 11, 1987, pp. 1636-1639. doi:10.1177/00220345870660110601

[15] D. C. Watts and J. D. Satterthwaite, "Axial ShrinkageStress Depends upon both C-factor and Composite Mass," Dental Materials, Vol. 24, 2008, pp. 1-8. doi:10.1016/j.dental.2007.08.007

[16] R. Guggenberger and W. Weinmann, "Exploring beyond Methacrylates," American Journal of Dentistry, Vol. 13, 2000, pp. 82-84.

[17] P. M. Chantler, X. Hu and N. M. Boyd, "An Extension of a Phenomenological Model for Dental Composites," Dental Materials, Vol. 15, No. 2, 1999, pp. 144-149. doi:10.1016/S0109-5641(99)00024-X

[18] A. J. Feilzer, L. H. Dooren, A. J. De Gee and C. L. Davidson, "Influence of Light Intensity on Polymerization Shrinkage and Integrity of Restoration-Cavity Interface," European Journal of Oral Sciences, Vol. 103, No. 5, 1995, pp. 322-326. doi:10.1111/j.1600-0722.1995.tb00033.x

[19] Y. Kinomoto, M. Torii, F. Takeshige and S. Ebisu, "Comparison of Polymerization Contraction Stresses between Self- and Light-Curing Composites," Journal of Dentistry, Vol. 27, No. 5, 1999, pp. 383-389. 


\section{doi:10.1016/S0300-5712(98)00065-7}

[20] J. S. Blalock, R. G. Holmes and F. A. Rueggeberg, "Effect of Temperature on Unpolymerized Composite Resin Film Thickness," Journal of Prosthetic Dentistry, Vol. 96, No. 6, 2006, pp. 424-432. doi:10.1016/j.prosdent.2006.09.022

[21] M. Trujillo, S. M. Newman and J. W. Stanbury, "Use of Near-IR to Monitor the Influence of External Heating on Dental Composite Photopolymerization," Dental Materials, Vol. 20, No. 8, 2004, pp. 766-777. doi:10.1016/j.dental.2004.02.003

[22] M. Daronch, F. A. Rueggeberg and M. F. de Goes, "Monomer Conversion of Pre-Heated Composite," Journal of Dental Research, Vol. 84, No. 7, 2005, pp. 663-667. doi:10.1177/154405910508400716

[23] M. Daronch, F. A. Rueggeberg, M. F. de Goes and R. Giudici, "Polymerization Kinetic of Pre-Heated Composite," Journal of Dental Research, Vol. 85, No. 1, 2006, pp. 38-43. doi:10.1177/154405910608500106

[24] N. Prasanna, Y. P. Reddy, S. Kavitha and L. L. Narayanan, "Degree of Conversion and Residual Stress of Preheated and Room-Temperature Composites," Indian Journal of Dental Research, Vol. 18, No. 4, 2007, pp. 173176. doi:10.4103/0970-9290.35827

[25] A. A. El Hejazi and D. C. Watts, "Creep and Visco-Elastic Recovery of Cured and Secondary-Cured Composites and Resin-Modified Glass-Ionomers," Dental Materials, Vol. 15, No. 2, 1999, pp. 138-143. doi:10.1016/S0109-5641(99)00023-8

[26] W. C. Oliver and G. M. Pharr, "An Improved Technique for Determining Hardness and Elastic Modulus Using Load and Displacement Sensing Indentation Experiments," Journal of Materials Research, Vol. 7, No. 6, 1992, pp. 1564-1574. doi:10.1557/JMR.1992.1564

[27] K. Nada and O. El-Mowafy, "Effect of Precuring Warming on Mechanical Properties of Restorative Composites," International Journal of Dentistry, Vol. 2011, 2011, Article ID: 536212. doi:10.1155/2011/536212

[28] C. A. Muñoz, P. R. Bond, J. Sy-Muñoz, D. Tan and J. Peterson, "Effect of Pre-Heating on Depth of Cure and Surface Hardness of Light-Polymerized Resin Composites," American Journal of Dentistry, Vol. 21, No. 4, 2008, pp. 215-222.

[29] R. R. Braga and J. L. Ferracane, "Contraction Stress Related to Degree of Conversion and Reaction Kinetics," Journal of Dental Research, Vol. 81, No. 2, 2002, pp. 114-118. doi:10.1177/154405910208100206

[30] M. Atai and D. C. Watts, "A New Kinetic Model for the Photopolymerization Shrinkage-Strain of Dental Composites and Resin Monomers," Dental Materials, Vol. 22, No. 8, 2006, pp. 785-791. doi:10.1016/j.dental.2006.02.009

[31] R. Walter, E. J. Swift, H. Sheikh and J. L. Ferracane, "Effect of Temperature on Composite Resin Shrinkage," Quintessence International, Vol. 40, 2009, pp. 843-847.

[32] M. Cadenaro, G. Marchesi, F. Antoniolli, C. Davidson, E. Dorigo and L. Breschi, "Flowability of Composites Is No Guarantee for Contraction Stress Reduction," Dental Ma- terials, Vol. 25, No. 5, 2009, pp. 649-654. doi:10.1016/j.dental.2008.11.010

[33] R. R. Braga, R. Y. Ballaster and J. L. Ferracane, "Factors Involved in the Development of Polymerization Shrinkage Stress in Resin-Composites: A Systematic Review," Dental Materials, Vol. 21, No. 10, 2005, pp. 962-970. doi:10.1016/j.dental.2005.04.018

[34] M. M. Stavridakis, D. Dietschi and I. Krejci, "Polymerization Shrinkage of Flowable Resin-Based Restorative Materials," Operative Dentistry, Vol. 30, 2005, pp. 118128.

[35] H. Y. Chen, J. Manhart, R. Hickel and K. H. Kunzelmann, "Polymerization Contraction Stress in Light-Cured Packable Composite Resins," Dental Materials, Vol. 17, No. 3, 2001, pp. 253-259. doi:10.1016/S0109-5641(00)00079-8

[36] H. Y. Chen, J. Manhart, K. H. Kunzelmann and R. Hickel, "Polymerization Contraction Stress in Light Cured Compomer Restorative Materials," Dental Materials, Vol. 19, No. 7, 2003, pp. 597-602. doi:10.1016/S0109-5641(02)00110-0

[37] L. G. Lovell, H. Lu, J. E. Elliott, J. W. Stanbury and C. N. Bowman, "The Effect of Cure Rate on the Mechanical Properties of Dental Resins," Dental Materials, Vol. 17, No. 6, 2001, pp. 504-511. doi:10.1016/S0109-5641(01)00010-0

[38] W. D. Cook, "Thermal Aspects of the Kinetics of Dimethacrylate Photopolymerization," Polymer, Vol. 33, No. 10, 1992, pp. 2152-2161. doi:10.1016/0032-3861(92)90882-W

[39] W. D. Cook, "Photopolymerization Kinetics of Oligo (Ethylene Oxide) and Oligo (Methylene) Oxide Dimethacrylates," Journal of Polymer Science Part A: Polymer Chemistry, Vol. 31, No. 4, 1993, pp. 1053-1067. doi:10.1002/pola.1993.080310428

[40] M. Cadenaro, M. Biasotto, N. Scuor, L. Breschi, C. L. Davidson and R. Di Lenarda, "Assessment of Polymerization Contraction Stress of Three Composite Resins," Dental Materials, Vol. 24, No. 5, 2008, pp. 681-685. doi:10.1016/j.dental.2007.06.031

[41] M. R. Bouschlicher, M. A. Vargas and D. B. Boyer, "Effect of Composite Type, Light Intensity, Configuration Factor and Laser Polymerization on Polymerization Contraction Forces," American Journal of Dentistry, Vol. 10, No. 2, 1997, pp. 88-96.

[42] A. Miguel and J. C. de la Macorra, "A Predictive Formula of the Contraction Stress in Restorative and Luting Materials Attending to Free and Adhered Surfaces, Volume and Deformation," Dental Materials, Vol. 17, No. 3, 2001, pp. 241-246. doi:10.1016/S0109-5641(00)00077-4

[43] C. S. Pfeifer, J. L. Ferracane, R. L. Sakaguchi and R. R. Braga, "Factors Affecting Photo-Polymerization Stress in Dental Composites," Journal of Dental Research, Vol. 87, No. 11, 2008, pp. 1043-1047. doi: $10.1177 / 154405910808701114$

[44] J. Li, H. Li and S. L. Fok, "A Mathematical Analysis of Shrinkage Stress Development in Dental Composite Restorations During Resin Polymerization," Dental Materials, Vol. 24, No. 7, 2008, pp. 923-931. 
doi:10.1016/j.dental.2007.11.012

[45] W. C. Wagner, M. N. Ascu, A. L. Neme, J. B. Linger, F. E. Pink and S. Walker, "Effect of Pre-Heating Resin Composite on Restoration Microleakage," Operative Dentistry, Vol. 33, No. 1, 2008, pp. 72-78. doi:10.2341/07-41
[46] I Elsayad, "Cuspal Movement and Gap Formation in Premolars Restored with Preheated Resin Composite," Operative Dentistry, Vol. 34, No. 6, 2009, pp. 725-731. doi:10.2341/09-012-L 